\title{
QUALITY IMPROVEMENT Strengthening citizenship: a healthcare improvement priority
}

\author{
Authors: Alan Cribb ${ }^{\mathrm{A}}$ and Alf Collins ${ }^{\mathrm{B}}$
}

We propose that strengthening citizenship could help realise some of the substantial changes that are being called for in mainstream health policies. We highlight the way that current healthcare improvement agendas entail, and depend upon, large-scale and complex cultural change. But, we suggest, there is a severe limit to how far such cultural change can be engineered from above or through conventional quality improvement methods. In summary, we argue that supporting what we call 'civic culture' - a culture that encourages and enables effective citizenship - may be a precondition for bringing about policy aspirations and related improvements.

KEYWORDS: citizenship, quality improvement, health policy, staff wellbeing

DOI: $10.7861 /$ fhj.2020-0122

\section{Introduction}

It has long been recognised that desired changes in healthcare are unlikely to come about unless people's energies and ideas are harnessed. ${ }^{1}$ Mary Dixon-Woods has summed this up recently by stressing the importance of 'coalitions of the willing' rather than 'diktats' both in quality improvement and in health policy more broadly. ${ }^{2}$ A number of key policy trends underline the critical importance of this insight and point towards a major implication, which we summarise as the need to strengthen 'civic culture' - ie a culture of citizenship - in health services (see Box 1 for summary definitions of these ideas and their relevance). We suggest that encouraging citizenship should now be seen as a priority for those who lead and work in healthcare. This emerging priority is not only supported by insights from quality improvement, but strongly resonates with established policy directions, including new models of care and collaboration, as well as discussions about staff wellbeing. The suggestion that citizenship is a healthcare priority may have seemed doubtful to many before the COVID-19 pandemic, but this should no longer be the case.

Authors: ${ }^{A}$ co-director of the Centre for Public Policy Research, King's College London, London, UK; ${ }^{B}$ Clinical director of Personalised Care Group, NHS England and NHS Improvement, London, UK

\section{Broader visions of improvement encompass cultural change}

Quality improvement in a narrow sense - or 'QI' - refers to a set of methods that have proved useful in defining, delivering and measuring specific improvements. These methods include, for example, the Institute for Healthcare Improvement's 'Model for Improvement', Lean and Six Sigma. Quality improvement in a broader sense treats QI as but one of a number of system supports that can underpin improvement - which include, for example, effective institutional leadership and management. These two senses converge in the widespread acceptance that

\section{Box 1. Summary account of citizenship and civic culture}

A citizen is a member of a community who, in principle, is in a position to help shape the shared life, direction and practices of that community. A civic culture is one that encourages and enables members to exercise the rights and duties of citizenship by fostering opportunities for individual and collective participation, including through critique, disagreement and shared deliberation. The idea of citizenship is typically applied to individuals' roles within a nation state, but it can also be applied to organisational, regional or more local affiliations. ${ }^{3,4}$

Everyone who works in and is served by healthcare organisations can be a citizen both of those organisations and of surrounding communities. This is not to deny that in practice opportunities and capabilities to exercise citizenship will vary substantially. For example, healthcare professional identities may sometimes give individuals an unusual degree of power or status within an organisation or community, but often professionals may themselves be relatively powerless and anonymous but still able to make a contribution. Similarly, both professionals and patients can act as citizens within healthcare organisations although their potential contributions will likely reflect differences in power and influence arising from their other specific identities and roles.

By necessity this is a brief simplified account which we believe is adequate for our purposes. There are competing models of citizenship and there are also important critiques that can be made of appeals to citizenship (eg as ways of indirectly controlling people or 'off-loading' responsibilities) but we leave these complications aside here. ${ }^{5}$ 
all successful improvement work depends upon attention to the contexts of improvement, including health system cultures.

One of the most striking and challenging features of mainstream currents in health policy is that they call for improvements that require fundamental cultural changes. Taken together, such changes would add up to a major reorientation or 'rebalancing' of the health system. ${ }^{6-8}$ For example, fundamental changes that are being routinely advocated for and pursued - in the NHS and in many other systems - include the following: greater integration of care across various boundaries including clinical care, social care and public health; more partnership working or even co-production between professionals and patients; more use of personalised models so that care is responsive to the concerns and perspectives of individuals; and more systematic attention to the social determinants of health.

All of these shifts in thinking and practice are being proposed as important healthcare improvements, but they do not fit neatly into a conventional QI paradigm. They are not about producing better widgets in existing healthcare boxes. If anything, they are about refashioning, and sometimes dispensing with, accepted widgets and boxes. QI has a role to play - a valuable supportive role in identifying effective methods and indicators of change but it is insufficient unless coupled with a more expansive view of improvement.

Yet there is a severe limit to how far complex cultural changes can be 'engineered' from above; almost by definition they need to be owned and lived out on the ground. In addition, foundational transformations cannot be achieved unless the methods adopted to implement them are suited to the changes being sought; to succeed they must embody the ideas and values that they espouse. The people who organise services and the professionals and others who make them work on the ground are being asked to form new kinds of relationships, to be more fully responsive to diverse needs and perspectives and to embrace new ways of thinking and acting. The levels of responsiveness and forms of flexible partnership being encouraged are not best advanced through standardised directives or protocols but require ongoing creativity, dialogue and debate; in other words, they require effective citizenship.

\section{Why citizenship matters}

A strong civic culture encourages and builds upon citizenship within communities and institutions. It fosters networks of relationships that enable joint deliberation and debate and underpin coordinated action. ${ }^{9,10}$ Talking about strengthening civic culture is similar to advocating for ideas such as 'distributed leadership' or 'communities of practice' but it is a more inclusive and far-reaching ambition. Like these other notions, it recognises the importance of utilising everyone's accumulated experience and capabilities and the crucial contribution of bottom-up participation and collaboration in practice development, but, in addition, it has relevance across very diverse settings and roles and can transcend organisational boundaries. Furthermore, it acknowledges disagreement as well as agreement as a potentially constructive principle.

The relevance of citizenship is unarguable in some contexts such as a public health crisis. But it also has obvious application in those ongoing policy currents that see healthcare institutions as principal actors within their geographical communities. The idea, developed in the US, of hospitals as 'anchor institutions', operating in partnership with other agencies and social movements to address the social determinants of health and deploy population resources, is increasingly prominent in the UK. ${ }^{11,12}$ This model clearly depends upon health professionals finding ways of working with other community citizens who have different perspectives, purposes and lines of accountability. Citizenship here is rooted in, but an extension of, professional collegiality. By necessity it means transcending professional boundaries and being ready to negotiate between conflicting kinds of concerns and claims. This may, for example, involve health services staff being responsive to, and willing to participate in, 'citizen-led' approaches to health planning and potentially re-designing services accordingly. The 'Wigan Deal', which has piloted this approach, also shows how this kind of collaboration and responsiveness requires considerable devolution of power to frontline staff. ${ }^{13}$ Citizenship and professionalism are thus not only complementary but can be combined. Civic culture, including civic professionalism, is a crucial counterweight to the top-down pressures of health service managerialism.

However, exactly the same arguments apply to the need for citizenship within healthcare organisations and systems. Calls for integration and co-production mean that health professionals need to work across internal health system boundaries and to forge forms of collaboration with colleagues and patient populations in ways that cross lines of expertise and authority. It clearly does not make sense to say that frontline staff should be empowered to think of themselves as citizens outside of their employing institutions but not within them. But the arguments for citizenship within healthcare systems are also practical. What underpins many of the deep-seated changes being advocated in healthcare is a recognition that biomedical approaches need to be combined with other approaches. In concrete terms, new policy directions are aiming to address a healthcare landscape in which, for example, older patients may have five different conditions and have been prescribed 15 different kinds of medication. In very many instances, such patients' interests will be best served by looking across the range of their needs and combining diverse professional and patient perspectives through an emphasis on shared decision-making, support for self-management and community assets. This requires complementing the reductionism of biomedical reasoning with synthesising processes - bringing together people and ways of thinking.

\section{Complexity requires inclusion and creativity}

In summary, greater responsiveness to patients and social contexts means that provision of healthcare becomes more complex, variegated and contested and this requires new capabilities, flexibilities and responsibilities from professionals. ${ }^{14}$ Indeed, once we have acknowledged the importance of respect for patients and patient inclusion the same logic also compels us to recognise the crucial role of respect for staff and staff inclusion. Luckily this need to attend to both the support and engagement of health services staff is increasingly accepted. It is found in discussions around staff wellbeing and also in a broader shift in emphasis away from managerialism. ${ }^{15}$ For example, the developing NHS 'People Plan' shows an interest not just in building a larger, more motivated and flexible staff but in the importance of culture change to support effective staff engagement. ${ }^{16}$ However, we suggest that the current discussions around the importance of staff may not get to the crux of what 
is needed. The change being called for is welcome; notably, it has been recognised that staff motivation that stems from extrinsic managerial norms and targets, especially where these work through fear, are suboptimal and that services that create and underpin a positive culture and inclusive and compassionate leadership are likely to offer more sustainable and high quality care. We would suggest, however, that insofar as this is interpreted as being about changing the mix of sticks and carrots it falls short of what is needed.

Health services that are more responsive and flexible will involve debate and disagreement as part of a healthy working culture. It might even be said that 'staff engagement' that does not result in a measure of disagreement has not started to work. There will still be a place for the tools of managerial change targeted investments, exemplar projects, reworked incentives and so on; such tools can make a contribution but only if staff are encouraged to engage with them critically, appropriate them, adapt them and even resist them in creative ways. Calling for this kind of shift may sound radical to some, but nothing less can deal with the complexity of current policy ambitions. On the other hand, perhaps it is not that much to ask. What we are talking about will probably seem quite familiar to anyone who has paid attention to high-functioning teams where inclusion and routine dialogue is core to what makes them work. ${ }^{17}$ It is also compatible with the conditions of success identified in the most insightful and carefully grounded QI scholarship. For example, Liberati et al's ethnography of an exceptionally safe maternity unit identifies the importance of 'organisational citizenship' as one of a range of factors that helps underpin successful improvement. ${ }^{18} \mathrm{Good}$ management welcomes citizenship and steers contestation away from undue conflict and towards something productive.

\section{Conclusion}

It is not easy to develop strategies for bolstering citizenship and this would be the subject for another and longer piece, but perhaps we can offer some indications here. In a nutshell it involves a shift in emphasis not just from top-down to bottom-up influence, but also from vertical to horizontal relationships. In part this means not equating the managerial hub of institutions with their 'centre'. Rather, wherever people come together to give and receive care, or to support one another, is a centre and can be a source of civic action. A key job for system and institutional leaders is not to stifle citizenship. This involves giving an absolute priority to establishing a climate of respect and recognition for everyone irrespective of formal position or role. It also means both inviting and welcoming input from across boundaries inside and outside healthcare institutions, and encouraging, valuing and harnessing grass roots activities and networks. The latter may be either or both social or professional in focus but can help build solidarity and trust and generate ideas and platforms for improving the way things are done. This is mirrored, for example, in Braithwaite's observation that 'all meaningful improvement is local, centred on natural networks of clinicians and patients'. ${ }^{14}$ Flourishing 'bottomup' networks would ideally result in 'speaking up' being seen as an unremarkable norm rather than as a virtue for exceptional circumstances.

Finally, we wish to underline the importance of this theme for staff wellbeing. There is now, quite rightly, a heightened concern about workforce wellbeing and sustainability. The importance of these concerns and ongoing efforts to engage staff and build inclusive models of working are reinforced when connected to the idea of citizenship. As has been stressed by many scholars since at least Aristotle, citizenship and wellbeing are closely interlinked: the more we are able to influence our activities and the ways they are defined and organised the more likely we are to feel valued and be fulfilled.

Position papers about 'resetting' healthcare in the wake of COVID-19 - including, where possible, holding on to lessons and successful innovations - only reinforce the importance of integrated care, including partnerships with communities and patients. ${ }^{19-21}$ Our specific recommendations are, first, that every time mechanisms of community involvement or co-production are rightly invoked or planned the same level of attention and priority is explicitly paid to staff participation, and, second, that in this process staff wellbeing is included as a core feature of quality. ${ }^{22}$ The latter not only because 'care' of staff matters but also because support for staff motivation and creativity is a prerequisite for progress. ${ }^{23}$ Many policy aspirations can now be advanced under the banner of supporting citizenship in health services. :

\section{Funding}

Alan Cribb is very grateful for Wellcome Trust funding (grant number 209811/Z/17/Z).

\section{References}

1 Deming WE. The new economics for government, industry, education. Cambridge: MIT Press, 1994.

2 Dixon-Woods M. How to improve healthcare improvement. BM] 2019;367:15514.

3 Bovens M. The quest for responsibility: accountability and citizenship in complex organisations. Cambridge: Cambridge University Press, 1998.

4 Packham C. Active citizenship and community learning. Exeter: Learning Matter, 2008.

5 Rose N. Community, citizenship and the third way. Am Behav Scientist 2000;43:1395-411.

6 Marshall M, Cornwell J, Collins A. Rethinking medicine. BMJ 2018;363:k4987.

7 Treadwell J, McCartney M. Overdiagnosis and overtreatment: generalists - it's time for a grassroots revolution. $\mathrm{Br}$ J Gen Pract 2016;66:116-7.

8 Montori V. Why we revolt. Rochester: The Patient Revolution, 2017.

9 Putnam RD. What makes democracy work? National Civic Review 1993;82:101-7.

10 Lichterman P. Reinventing the concept of civic culture. In: Alexander JC, Jacobs RN, Smith P (eds), The Oxford handbook of cultural sociology. Oxford Handbooks Online, 2017.

11 Franz B, Skinner D, Wynn J, Kelleher K. Urban hospitals as anchor institutions: frameworks for medical sociology. Socius 2019;5:1-10.

12 Reed S, Göpfert A, Wood S et al. Building healthier communities: the role of the NHS as an anchor institution. The Health Foundation, 2019. www.health.org.uk/publications/reports/ building-healthier-communities-role-of-nhs-as-anchor-institution

13 Naylor C, Wellings D. A citizen-led approach to health and care: lessons from the Wigan deal. The King's Fund, 2019. www. kingsfund.org.uk/publications/wigan-deal

14 Braithwaite J. Changing how we think about healthcare improvement. BMJ 2018;361:k2014.

15 Perlo J, Balik B, Swensen S et al. IHI framework for improving joy in work. Cambridge, Massachusetts: Institute for Healthcare Improvement; 2017. 
16 NHS. Interim NHS people plan. NHS, 2019. Available from www. longtermplan.nhs.uk/publication/interim-nhs-people-plan/.

17 Harchowal J. Creating a common purpose and a supportive culture. King's Fund, 2020. www.kingsfund.org.uk/audio-video/commonpurpose-culture-jatinder-harchowal.

18 Liberati EG, Tarrant C, Willars ] et al. How to be a very safe maternity unit: An ethnographic study. Soc Sci Med 2019;223:64-72.

19 World Health Organization, International Federation of Red Cross and Red Crescent Societies, United Nations Children's Fund. Community-based health care, including outreach and campaigns, in the context of the COVID-19 pandemic. WHO, 2020. www.who.int/publications/i/item/WHO-2019-nCoV-Comm_ health_care-2020.1

20 Royal College of Physicians. Rebuilding the NHS - RCP priorities for the resetting of services. RCP, 2020. www.rcplondon.ac.uk/ guidelines-policy/rebuilding-nhs-rcp-priorities-resetting-services
21 Butler SM. After COVID-19 - Thinking differently about running the health care system. JAMA 2020;323:2450-1.

22 Feeley D. The triple aim or the quadruple aim? Institute for Healthcare Improvement, 2017. www.ihi.org/communities/blogs/ the-triple-aim-or-the-quadruple-aim-four-points-to-help-set-yourstrategy

23 Bodenheimer T, Sinsky C. From triple to quadruple aim: care of the patient requires care of the provider. Annals Fam Med 2014;12:573-6.

Address for correspondence: Prof Alan Cribb, Centre for Public Policy Research, King's College London, Franklin-Wilkins Building WBW, London SE1 9NH, UK.

Email: alan.cribb@kcl.ac.uk

Twitter: @phil4hcq 